Canadian Geotechnical Journal

Canadian

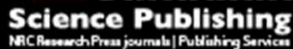

Revue canadienne de géotechnique

\title{
Swelling phenomena and effective stress in compacted expansive clays
}

\begin{tabular}{|r|l|}
\hline Journal: & Canadian Geotechnical Journal \\
\hline Manuscript ID: & cgj-2014-0479.R1 \\
\hline Manuscript Type: & Article \\
\hline Date Submitted by the Author: & 16-Apr-2015 \\
\hline Complete List of Authors: & $\begin{array}{l}\text { Mašín, David; Charles University in Prague, Faculty of Science } \\
\text { Khalili, Nasser; University of New South Wales }\end{array}$ \\
\hline Keyword: & expansive clay, bentonite, effective stress, swelling pressure \\
\hline \multicolumn{2}{|l}{} \\
\hline
\end{tabular}




\title{
Swelling phenomena and effective stress in compacted expansive clays
}

\author{
David Mašín, Charles University in Prague, Czech Republic \\ Nasser Khalili, University of New South Wales, Sydney, Australia \\ corresponding author: \\ David Mašín \\ Charles University in Prague \\ Faculty of Science \\ Albertov 6 \\ 12843 Prague 2, Czech Republic \\ E-mail: masin@natur.cuni.cz \\ Tel: +420-2-2195 1552, Fax: +420-2-21951556
}

July 9, 2015

Manuscript accepted for publication in

Canadian Geotechnical Journal 


\begin{abstract}
The central aim of the paper is to discuss the applicability of the effective stress principle as defined by Terzaghi (total stress minus pore water pressure) to predict the behaviour of expansive clay aggregates. Phenomena occurring between individual clay minerals are reviewed first at the molecular level obtained in the colloid science research. In particular, it is noted that, for inter-particle distances higher than approx. $1.5 \mathrm{~nm}$, the pore water pressure in bulk equilibrium solution forms an additive component of the inter-particle disjoining pressure. It is concluded that for these distances the Terzaghi's effective stress principle should be adequate to describe the clay behaviour. To support the developments, an extensive experimental database of nine different sodium and calcium bentonites available in publishhed literature was analysed. With the aid of double structure constitutive modelling, procedures were developed to extract the information on the behaviour of clay aggregates from the experimental measurements. It was then shown that unconfined water retention curves, swelling pressure tests, swelling under constant load tests and mechanical unloading tests are all uniquely related in terms of the dependency of dry density (or void ratio) of clay aggregate vs. mean effective stress. By considering reversibility of aggregate behaviour and full saturation of aggregates, this implies that the effective stress principle is valid in predicting expansive clay aggregate volumetric deformation.
\end{abstract}

Keywords: expansive clay; bentonite; effectives stress; swelling pressure.

\title{
Introduction
}

Compacted bentonites are clays with a high smectite content and they have received considerable research attention in the past, particularly due to their application in engineered barrier systems for high-level nuclear waste repositories. Various models have been developed to reproduce their swelling behaviour. The empirical models relate the swelling pressure developed under confined swelling (Nayak and Christensen 1971, Low 1979) or swelling strain under constant load (Yevnin and Zaslavsky 1970, Buzzi et al. 2007, Buzzi and Giacomini 2010, Buzzi 2010) to the clay dry density or to the inter-particle distance under the assumption of homogeneous and parallel particle distribution. Another group of models is based on the diffuse double layer theory, attributed to Gouy (1910) and Chapman (1913) in its basic form. The dependency of swelling pressure on inter-particle distance is calculated through quantification of the repulsive and attractive forces caused by physico-chemical effects at the particle scale level. The basic form of the diffuse double layer theory is only applicable for smectite particles suspended in monovalent electrolyte solutions at low concentrations 
(Warkentin and Schofield 1958, Yong et al. 1963, Sridharan and Jayadeva 1982, Zhang et al. 1993, Yong 1999a, Yong 1999b, Komine and Ogata 2004, Mitchell and Soga 2005, Phillips and Tripathy 2011, Liu 2013). For different cation types and higher densities, various modifications to this theory have been proposed (Yong and Mohamed 1992, Komine and Ogata 1999, Sridharan and Choudhury 2002, Tripathy et al. 2004), including numerical studies using the finite element method (Smith et al. 2009) and the discrete element method (Katti et al. 2009). An essential component of these models is the evaluation of the mid-point electrical potential between two parallel clay particles. This potential, which primarilly controls the inter-particle repulsion, is controlled by the ionic strength of pore water (and thus depends on osmotic suction in equilibrium solution). It can be balanced either by the matric potential or by the external load, which is then denoted as a swelling pressure. In principle, it is possible to by-pass the description of the inter-layer phenomena and directly relate the swelling pressure to the soil water potential. Such an approach has been adopted in the continuum thermodynamic models of Low and Anderson (1958), Sposito (1972), Oliphan and Low (1982), Dueck and Börgesson (2007) and Lempinen (2011).

The above models relate the swelling pressure/water potential to inter-particle distance and assume that the particle distribution is homogeneous, in which case the inter-particle distance can be calculated from the specific surface area and global dry density of the material. The actual structure of a compacted clay is, however, more complex. It is formed by clay particle clusters (hereafter referred to as aggregates), which form the primary component of a rather complex structure (Fig. 1). The structure schematically depicted in Fig. 1 has been justified by various experimental and numerical studies, see Mašín (2013) for a detailed review. In order to predict the mechanical response of such a material, models that explicitly consider two structural levels have been developed by several authors (Gens and Alonso 1992, Yang et al. 1998, Alonso et al. 1999, Thomas and Cleall 1999, Sánchez et al. 2005, Mašín 2013). The double structure models often assume a simple representation of the aggregate response; that is (1) the Terzaghi's effective stress is assumed to be valid, (2) the behaviour of the aggregate is assumed to be reversible elastic and (3) the aggregate is assumed to be fully saturated. The focus of this paper is the issue of the applicability of the Terzaghi's effective stress.

Throughout the paper, the following terminology is adopted, which is also identified in Fig. 1. The notion of a clay layer represents a 2:1 TOT (tetrahedral-octahedral-tetrahedral) sandwich layer of clay mineral crystals. The notion of a clay particle represents a stack of clay layers inter-connected by up to four layers of crystaline water. An assembly of clay particles, denoted as the clay aggregate, forms the unit of the compacted clay double structure. 


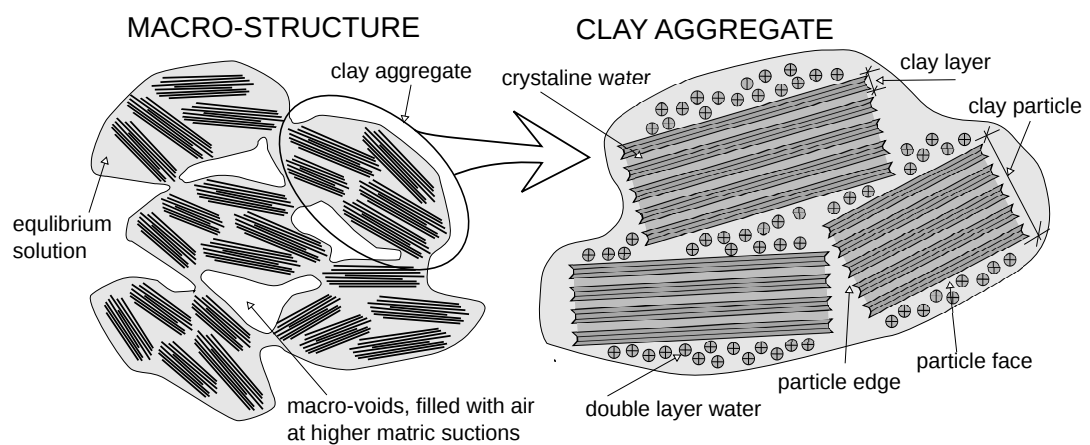

Figure 1: Schematic representation of the structure of a compacted clay and of the adopted terminology.

An assembly of aggregates is denoted as the macro-structure, while the voids between the aggregates are denoted as macro-voids. The part of the clay particle surface parallel to the clay layers is denoted as the particle face. The portion of the clay particle surface normal to the particle face is denoted as the particle edge. Diffuse double layers form around particle faces, with the bound water denoted as double layer water. The water beyond the diffuse double layers is denoted as the equilibrium solution. Note that there is no strictly defined boundary between the double layer water and equilibrium solution. Instead, ion concentration gradually decreases with distance from the clay particle, finally reaching a concentration of the equilibrium solution.

\section{Effective stress in compacted clays - review of current under- standing}

The concept of effective stress, introduced by Terzaghi (1936), transforms a multiphase porous medium into a mechanically equivalent single-phase continuum. It therefore provides a powerful unifying reference for the analysis of soils as multiphase porous media. For saturated soils, Terzaghi (1936) introduced the effective stress in the form

$$
\sigma^{\prime}=\sigma^{t o t}-u_{w}
$$

where $\sigma^{\prime}$ is the effective stress, $\sigma^{t o t}$ is the total external stress and $u_{w}$ is the pore water pressure $^{1}$.

\footnotetext{
${ }^{1}$ Note that tensorial formulation of Eq. (1) reads $\boldsymbol{\sigma}^{\prime}=\boldsymbol{\sigma}^{t o t}-\mathbf{1} u_{w}$, where $\mathbf{1}$ is a second-order identity tensor and $\boldsymbol{\sigma}^{\prime}$ and $\boldsymbol{\sigma}^{\text {tot }}$ are effective and total stress tensors respectively.
} 
In the more general case of partially saturated soils with variable fluid chemistry, pore water pressure is only one component of the total energy status of the pore water. Matric potential, measured by matric suction $s_{m}=u_{a}-u_{w}$ (where $u_{a}$ is the pore air pressure), represents the potential of the pore water with respect to water of the same chemistry at ambient atmospheric conditions; this is related to the air-water interfacial tension phenomena in unsaturated soils. Osmotic potential, measured by osmotic suction $s_{\pi}$, represents the potential of the pore water at ambient atmospheric conditions with respect to pure water at ambient atmospheric conditions. Osmotic suction is proportional to the molar concentration of chemical species present in the solution. Total suction $s_{t}$ is the sum of the osmotic and matric components (among other components, which can however be neglected in the present analyses). Matric suction can also be adopted in the description of saturated soil with negative pore water pressure, in which case the matric suction is equal to minus the pore water pressure.

Central to the present work is the effective stress concept, whose very deffinition is interpreted in different ways by various authors. Terzaghi (1936) stated that "all measurable effects of a change of stress, such as compression, distortion, and a change in shearing resistance of a soil are due exclusively to changes in effective stress". It was soon understood that most soils, in fact, do not follow this definition. By example, Leonards (1962) pointed out that during creep (deforming soil under constant effective stress), the soil does not obey the effective stress principle in a strict sense. There is a number of other similar examples in soil mechanics. Apart from the secondary compression (1), we may list wetting-induced compaction of partially saturated soils (2); thermally-induced soil deformation (3); whethering-induced soil compaction (4) (Nova et al. 2003); deformation of clayey soil induced by variation of osmotic suction under constant matric suction (5).

Regardless of the fact that Leonards (1962) is correct that the Trezaghi's principle looses its validity in a strict sense for predicting the secondary compression phenomena, the equation (1) can still be used with advantage for constructing constitutive models (see, by example, Niemunis et al. 2009). Similarly, the concept of effective stress can be used for predicting the other phenomena listed above: the additional deformation may be treated either by incorporating additional elastic or plastic mechanism into the model, or (in some cases) by modifying the effective stress equation itself. Relevant for this paper is mechanism (6) (deformation of clayey soil induced by variation of osmotic suction). Here, we follow the first of the two approaches, while we point out that, in principle, incorporating the osmotic suction into the effective stress equation would also be possible. 


\section{Water in fine pores of clayey soils}

The effective stress expression (1) has generally been accepted as representing the behaviour of saturated soils with free pore water, provided that the compressibility of the solid particles is negligible (Biot 1941, Skempton 1960, Nur and Byerlee 1971). A more complicated situation arises in the case of fine-grained soils, where a significant amount of water is tightly bound to the solid particles by physico-chemical phenomena at the molecular scale. Water in clayey soils exists in three basic states (Madsen and Müller-Vonmoos 1989): (1) Crystalline water, which is tightly bound within the structure of the clay particle in the inter-layer space; (2) double layer water, present between individual clay particles as part of the diffuse double layers and (3) equilibrium solution. For soils with larger inter-particle distances, the double layer water gradually becomes equilibrium solution with increasing distance from the particle surface due to gradually decreasing concentration of ions.

The amount of crystalline water depends on the matric forces (Yong 1999b) and is insensitive to the pore water chemical properties (Herbert and Moog 2000). Hydration with the crystalline water occurs in steps corresponding to the molecular layers of water (maximum of 3 to 4 layers) and is dependent on the major exchangeable cation type (Farmer and Russell 1971, Ferrage et al. 2005, Zheng et al. 2010). For example, Na-montmorillonite hydrates step-wise within a high relative humidity range (approx. 20\%-100\%, Devineau et al. 2006), whereas Ca-montmorillonite becomes hydrated at low relative humidities (high total suctions) and remains essentially intact with further wetting (Villar 2007, Morodome and Kawamura 2009). The step-wise hydration was explained by Israelachvili and Pashley (1983), who attributed it to deviations from the diffuse double layer theory at distances very close $(<1.5 \mathrm{~nm})$ to the clay particle surfaces. The dependency of inter-particle forces on distance becomes oscillatory at distances below $1.5 \mathrm{~nm}$ and their minima correspond to stable states with one, two or three layers of crystalline water.

The diffuse double layer water is bound to the cation cloud that forms around negatively charged clay particles where hydration due to suction decrease depends on the clay mineralogical composition. During hydration Na-montmorillonite breaks apart into clay particles with variable number of layers due to diffuse double layer repulsion. For example, Saiyouri et al. (2004) observed that the particle size decreased from 350 layers to 10 layers when suction was reduced from $100 \mathrm{MPa}$ to $1 \mathrm{kPa}$. On the other hand, Ca-montmorillonite remains more stable after saturation with crystalline water (Madsen and Müller-Vonmoos 1989, Mitchell and Soga 2005). The diffuse double layer size depends on the ion concentration in the equilibrium solution; it is thus directly related to osmotic suction (Callaghan and Ottewill 1974, Yong 1999b, Pusch 2006). An increase in the osmotic suction decreases the diffuse dou- 
ble layer size, and consequently, for the given inter-particle distance, it decreases the particle repulsion when the layers overlap.

\section{Existing effective stress models}

The stress state in highly compacted clays is often considered to be composed of two parts: "mineral stress" $\left(\sigma^{m}\right)$ which is transferred through the crystal structure of the clay mineral by means of edge-to-face contacts, and "inter-particle stress" $\left(\sigma^{R-A}\right)$, transferred through diffuse double layers and crystalline water layers acting at face-to-face contacts. The interparticle stress represents the electrostatic component of the disjoining pressure, and is equal to the difference between attractive (London van der Waals) and repulsive (in particular diffuse double layer) forces between the clay particles. Both these stresses contribute to the so-called structural stress $\sigma^{s}$, overall stress transferred by the clay structure.

Various authors have suggested different simplified models of the clay structure with the aim of isolating the $\sigma^{R-A}$ and $\sigma^{m}$ stress components from the structural stress $\sigma^{s}$. These models were classified by Hueckel (1992a). In the parallel models, the strains in the inter-particle spaces and in the mineral skeleton are assumed to be equal. Thus, the structural stress may be considered as the sum of the mineral and inter-particle components (Fig. 2a). The models by Lambe $(1958,1960)$ and Lu and Likos $(2006)$ consider $\sigma^{s}$ to represent the effective stress, whereas the models by Balasubramonian (1972), Sridharan and Venkatappa Rao (1973) and Morgernstern and Balasubramonian (1980) consider the effective stress to be represented by the mineral stress $\sigma^{m}=\sigma^{s}-\sigma^{R-A}$. This form of effective stress has been supported by Murad and Cushman (1996), Bennethum et al. (1997) and Moyne and Murad (2006) using the thermodynamic hybrid mixture theory of (Hassanizadeh and Gray 1979). Sridharan and Venkatappa Rao (1979) evaluated the parallel model of the latter type using shear strength data obtained by varying the dielectric constant of the pore medium. The cohesion intercept varied with the pore fluid type used, indicating that the structural stress, which was independent of the pore fluid chemistry, could not correctly predict the variation of shear strength under variable osmotic suction. This model was also adopted by Fam and Santamarina (1996).

Contrary to the parallel formulation, the series models (Bolt 1956, Hueckel 1992a) consider the structural stress, mineral stress and the inter-particle stress to be equal, while deformations in each of the components may be different (see Fig. 2b). In this case the structural stress is considered to represent the effective stress. A similar explanation for the effective stress within dense water-saturated Na-bentonite has been provided by Pusch (1982). He observed that under a given pore water chemistry the shear strength, as well as the elastic 
response, could be interpreted uniquely in the $\sigma^{s}$ space. Hueckel (1992a) argued that the parallel model of the $\sigma=\sigma^{m}$ type is suitable for prevailing edge-to-face particle contacts. On the other hand, the series model is, in his view, more suitable for representing face-to-face particle arrangements, which is relevant for highly compacted clays (Emerson 1962, Pusch 2006).

Sridharan and Venkatappa Rao (1973) argued that the shear resistance of the soil is controlled by the mineral stress $\sigma^{m}$, which, in their view, should be considered as the effective stress. However, they did not consider the shear resistance of the inter-layer and inter-particle spaces. Studies of the shear forces within molecular thin films indicate that the shear strength of the inter-particle space is dependent on the inter-particle distance. The inter-particle water does not transfer shear stresses for inter-particle distances larger than 7-10 molecular layers of water (1 molecular layer represents an approximate distance of $0.3 \mathrm{~nm}$, Saiyouri et al. 2000). With decreasing distance, water progressively changes its properties from a Newtonian viscous fluid to solid-like behaviour (Israelachvili et al. 1988, Schoen et al. 1989, Homola et al. 1989, Cushman 1990, Gee et al. 1990). Water then has a yield point and the shear stress no longer depends on the shear rate. If the shear viscosity of the molecular film is back-calculated using its shear strength properties (although the viscosity concept actually breaks down), it is 5-7 orders of magnitude higher than its bulk value (Gee et al. 1990). Such an increase in viscosity is also much higher than indicated by Allam and Sridharan (1984) in their arguments against the use of face-to-face contact-based shearing resistance models for clays.

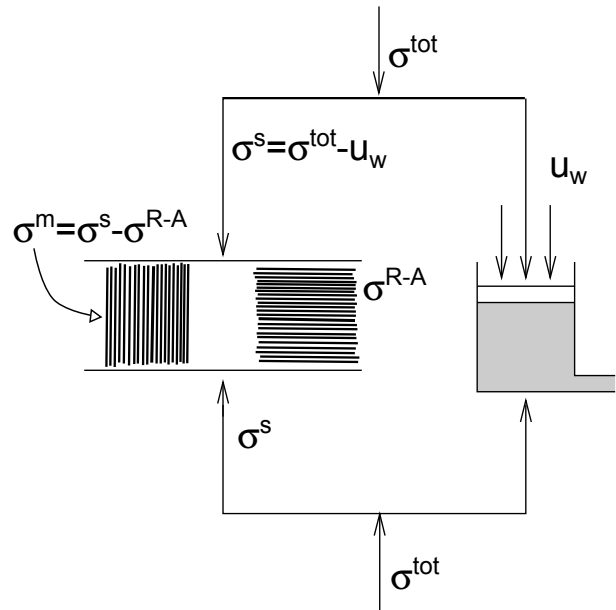

(a)

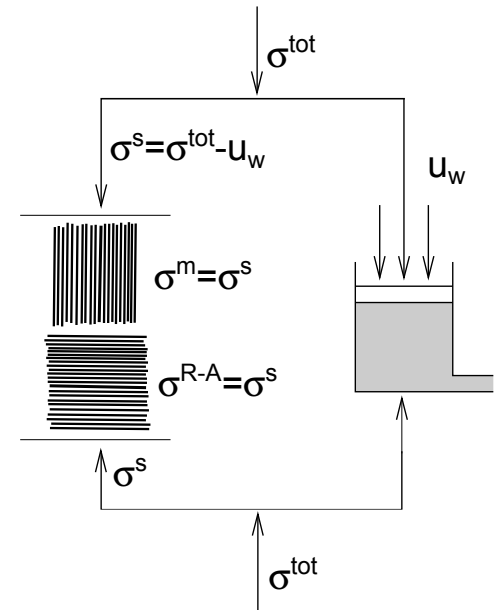

(b)

Figure 2: Different models for the stress state within the soil element. (a) parallel connection model, (b) series connection model. 


\section{Proposed interpretation of the effective stress in clay aggre- gates}

In order to decide whether the Terzaghi's effective stress principle is applicable to the behaviour of clayey soils, it is necessary to observe in greater detail the pressure field in thin water films between clay particles. This problem has been studied by interface scientists working on colloids. Derjaugin et al. (1987) presented a solution for the mechanical volumetric force balance equation within a film of water between two charged surfaces embedded in an equilibrium solution. They have shown that the pressure normal to the clay particle can be expressed as

$$
p_{N}^{p}=u_{w}+p^{R-A}
$$

where $p_{N}^{p}$ is the inter-particle pressure, $u_{w}$ is the hydrostatic pressure in the equilibrium solution and $p^{R-A}$ is the disjoining pressure containing, additively, the electrostatic diffuse double layer repulsive forces, the structural repulsive component (active at short distances only) and the attractive London van der Walls forces. For larger particle distances, $p^{R-A}$ diminishes and the inter-particle pressure is equivalent to that in the equilibrium solution, i.e. to $u_{w}$. Similar reasoning regarding the influence of pore pressure in shale has been presented by Gonçalvès et al. (2010).

Eq. (2) reveals that $u_{w}$ forms one component of the overall stress balance in a parallel assembly of particles loaded in the normal direction irrespective of the distance between the individual particles. To ensure that the system of particles is in static equilibrium, the inter-particle pressure must be balanced by the total external stress $p_{N}^{t}$, that is $p_{N}^{t}=p_{N}^{p}$. Therefore,

$$
p_{N}^{t}=u_{w}+p^{R-A}
$$

which can be rearranged and written in the rate form as

$$
\dot{p}^{R-A}=\dot{p}_{N}^{t}-\dot{u}_{w}
$$

where the dot is a rate operator $(\dot{x}=\partial x / \partial t, t$ being time). Eq. (4) implies that if the rate of total stress $\dot{p}_{N}^{t}$ is the same as the rate of pore water pressure $\dot{u}_{w}$, then $\dot{p}^{R-A}=0$. Since the $p^{R-A}$ magnitude is, for constant pore water chemistry, dependent only on the inter-particle distance, $\dot{p}^{R-A}=0$ implies that there is no change in the inter-particle distance and thus no volumetric deformation of the soil.

The above analysis implies that an assembly of clay particles in face-to-face contact loaded in the direction normal to the particle surface satisfies Terzaghi's effective stress principle. 
The molecular-scale forces causing a disjoining pressure $p^{R-A}$ then affect the compressibility of the system. By assuming that the system of particles with prevailing edge-to-face contact also satisfies Terzaghi's effective stress principle, it is possible to generate the general effective stress model depicted in Fig. 3. As in the series connection model shown in Fig. 2b, the effective stress in the clay grain assembly is equal to the structural stress calculated by

$$
\sigma^{s}=\sigma^{t o t}-u_{w}
$$

Unlike in the series model, however, it is not assume here that the mineral stress $\sigma^{m}$ and the inter-particle stress $\sigma^{R-A}$ are necessarily equal. While the relative distribution of different contact types within the specimen affects mechanical properties of the soil (edge-to-face contacts and face-to-face contacts have different compressibilities and shearing resistances), it is not relevant for the effective stress quantification.

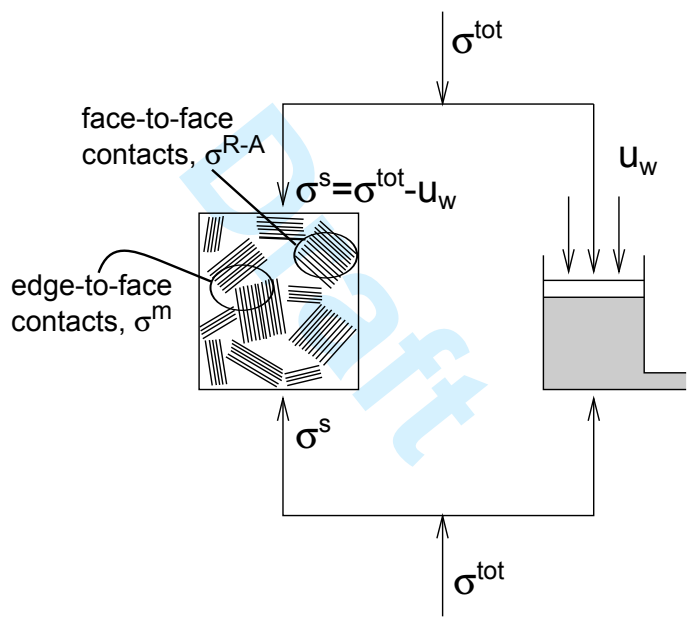

Figure 3: Proposed global description of the stress state within the soil element.

From a constitutive modelling perspective, such an approach to the effective stress allows us to use standard procedures adopted in structured clay modelling. Constitutive models may be defined within the Terzaghi's effective stress space. The relative proportions of the edgeto-face and face-to-face contacts affecting the overall mechanical properties of the assembly, can then be considered by means of state variables describing the soil fabric. It is outside the scope of the present paper to list all the possible variables, but the void ratio is the most important one (but not the only one). While void ratio is insufficient to describe the structural arrangement of particles, it is important to characterise the overall density of particles, which affects the relative proportion of edge-to-face and face-to-face contacts. The other suitable variable is the specific surface area, representing the size of the individual particles. As 
pointed out by Aylmore et al. (1970), surface area (when measured by nitrogen and carbon dioxide sorption) does not involve the inter-layer space and it is thus representative of the particle size.

When variable fluid chemistry is considered, another state variable that has to be taken into account is osmotic suction in equilibrium solution. This does not affect the validity of Eq. (3), but it does control the dependency of the disjoining pressure $p^{R-A}$ on the inter-particle distance, thus controlling the soil compressibility. In addition, osmotic suction variation can induce soil deformation under constant effective stress (in the same way as, for example, temperature). With osmotic suction being a state variable in a constitutive model (rather than being part of the effective stress formulation), one can represent the data of Sridharan and Venkatappa Rao (1979) discussed above (i.e., cohesion is dependent on fluid chemistry). Similar reasoning to that outlined in the present paper was proposed by Lu and Likos (2006), but they resorted back to the parallel type model formulation. The interpretation suggested in this work supports the modelling approach adopted by Hueckel (1992b), Kaczmarek and Hueckel (1998) and Loret et al. (2002), who used Terzaghi's's effective stress based constitutive model with additional chemically-induced strain added to the mechanical strain. This work, however, is not restricted to the series model interpretation, which assumes $\sigma^{\prime}=\sigma^{m}=\sigma^{R-A}$. Any stress distribution bounded by the limit cases of parallel and series models is admitted, but point out that an understanding of the internal mechanisms is not needed to interpret the soil response in global terms.

It is noted that the diffuse double layer theory leading to Eq. (2) is inaccurate when distances between the clay particle surfaces is very small $(<1.5 \mathrm{~nm})$, as pointed out by Israelachvili and Pashley (1983). This minimum inter-particle distance is thus considered as a possible limit to the validity of the proposed approach. Dry densities corresponding to this limit may be approximately quantified using equation due to Bolt (1956). The void ratio can be calculated using

$$
\rho_{d}=\frac{\rho_{s}}{1+\rho_{s} A_{s} d_{1 / 2}}
$$

where $\rho_{s}$ is a soil particle density $\left[\mathrm{kg} / \mathrm{m}^{3}\right], A_{s}$ is a specific surface area $\left[\mathrm{m}^{2} / \mathrm{kg}\right]$ and $d_{1 / 2}$ is one-half of the separation distance between particles $[\mathrm{m}]$. As indicated by Mitchell and Soga (2005), specific surface area of smectites exclusive of interlayer zones ranges from 50 to 120 $\mathrm{m}^{2} / \mathrm{g}$ (the secondary specific surface area that is exposed by expanding the lattice so that polar molecules can penetrate between layers can be up to $840 \mathrm{~m}^{2} / \mathrm{g}$ ). For our purposes, the $A_{s}$ exclusive of interlayer zones is relevant. For the upper bound $A_{s}=120 \mathrm{~m}^{2} / \mathrm{g}$, for $\rho_{s}=2.7$ $\mathrm{g} / \mathrm{cm}^{3}$ and $d_{1 / 2}=0.75 \mathrm{~nm}$, Eq. (6) yields the dry density of $2.2 \mathrm{~g} / \mathrm{cm}^{3}$. This dry density is higher than the dry densities of clay embedding canisters in the planned nuclear waste 
disposal applications, which are expected in the range between 2 and $2.1 \mathrm{~g} / \mathrm{cm}^{3}$ (Pusch 1982, Pusch 2006). It must however be also pointed out that the assumed parameters (and the Eq. (6) itself) leading to the limitting value of $2.2 \mathrm{~g} / \mathrm{cm}^{3}$ were only approximate and depend on the soil type.

A possible manifestation of this limitation is the experimental data set presented by Bucher and Müller-Vonmoos (1989), who studied compacted bentonites under the condition of zero deformation (and thus a constant value of $p^{R-A}$ ) and imposed a pore water pressure increase measuring the total stress response in terms of the ratio $\Delta \sigma^{t o t} / \Delta u_{w}$. The Terzaghi's effective stress implies the ratio $\Delta \sigma^{t o t} / \Delta u_{w}$ to be equal to one. However, Bucher and MüllerVonmoos (1989) observed that the ratio $\Delta \sigma^{t o t} / \Delta u_{w}$ attained values lower than one, even for dry densities below $2 \mathrm{~g} / \mathrm{cm}^{3}$.

\section{Investigation of the experimental data from available literature}

\section{Soils studied}

Experimental data on a number of different compacted clays, mostly Na- or Ca-montmorillonitic bentonites, have been used in the investigations. These investigations include five primarily sodium montmorillonitic bentonites, three primarily calcium montmorillonitic bentonites, and one bentonite composed of an interstratified calcium beidellite and kaolinite. Experimental data was obtained from the following sources:

- Avonseal bentonite: Graham et al. (1989).

- FEBEX bentonite: Villar (2002).

- FoCa7 bentonite: Cui et al. (2002), Delage et al. (1998) and Van Geet et al. (2009).

- Bavaria bentonite: Baille et al. (2010).

- Kunigel V1 bentonite: JNC (2000), Komine (2004).

- Volclay bentonite: Komine (2004).

- Kunibond bentonite: Komine (2004).

- Neokunibond bentonite: Komine (2004).

- MX-80 bentonite: Johannesson et al. (1999).

It should be pointed out that different soils were tested in different soil mechanics laboratories, which may cause inconsistencies in the relative comparison of different experimental data sets. Evaluation of the relative measurement error is outside the scope of the present paper. It is to be pointed out, however, that different experiments within a single experimental set (for the given soil) were performed in the same soil mechanics laboratory, different data on 
particular soil should thus be directly comparable.

The primary chemical and mineralogical compositions of the soils tested are summarised in Table 1. It is noted that, in some cases, the literature used to extract the experimental data did not contain sufficient information on the soil mineralogical composition. In these cases, composition data was obtained from other sources that described the same or a similar soil. The references used for the soil composition data are cited in the footnote of Table 1.

Table 1: Mineralogical and chemical composition of the soils studied. $M$ - montmorillonite, $B$ - beidellite, $K$ - kaolinite, CEC - cation exchange capacity.

\begin{tabular}{|c||c|c|c||c|c|c|c|}
\hline bentonite & $\begin{array}{c}\text { smectite } \\
\text { content [\%] }\end{array}$ & $\begin{array}{c}\text { dominant } \\
\text { smect. min. }\end{array}$ & $\begin{array}{c}\text { dominant } \\
\text { ex. cation }\end{array}$ & $\left.\begin{array}{c}\text { CEC } \\
{\left[\frac{\mathrm{meq}}{100 \mathrm{~g}}\right.}\end{array}\right]$ & $\left.\begin{array}{c}\mathrm{Na} \\
{\left[\frac{\mathrm{meq}}{100 \mathrm{~g}}\right.}\end{array}\right]$ & $\left.\begin{array}{c}\mathrm{Ca} \\
{\left[\frac{\mathrm{meq} .}{100 \mathrm{~g}}\right.}\end{array}\right]$ & $\left.\begin{array}{c}\mathrm{Mg} \\
{\left[\frac{\mathrm{meq} .}{100 \mathrm{~g}}\right.}\end{array}\right]$ \\
\hline Avonseal $^{1}$ & 79 & $\mathrm{M}$ & $\mathrm{Na}$ & 82 & 41 & 35 & 6 \\
Bavaria $^{2}$ & 60 & $\mathrm{M}$ & $\mathrm{Ca}$ & 74 & & 65 & 36 \\
FEBEX $^{3}$ & 92 & $\mathrm{M}$ & $\mathrm{Ca}$ & 111 & 25 & 47 & 3 \\
FoCa7 $^{4}$ & 80 & $\mathrm{~B}+\mathrm{K}^{5}$ & $\mathrm{Ca}$ & 69 & 3 & 63 & \\
Kunibond $^{6}$ & 80 & $\mathrm{M}$ & $\mathrm{Ca}$ & 80 & 12 & 59 & 7 \\
Kunigel V1 $^{6}$ & 48 & $\mathrm{M}$ & $\mathrm{Na}$ & 73 & 41 & 29 & 3 \\
MX-80 $^{7}$ & 83 & $\mathrm{M}$ & $\mathrm{Na}$ & 88 & 67 & 8 & 5 \\
Neokunibond $^{6}$ & 76 & $\mathrm{M}$ & $\mathrm{Na}$ & 104 & 62 & 33 & 6 \\
Volclay $^{6}$ & 69 & $\mathrm{M}$ & $\mathrm{Na}$ & 101 & 57 & 29 & 13 \\
\hline
\end{tabular}

${ }^{1}$ JNC (2000); ${ }^{2}$ Baille, Tripathy, and Schanz (2010); ${ }^{3}$ Villar (2002); ${ }^{4}$ Saiyouri et al. (2000); ${ }^{5}$ FoCa7 clay composed of kaolinite interstratified with the beidellite in equal proportion (Van Geet et al. 2009); ${ }^{6}$ Komine (2004); ${ }^{7}$ Karnland et al. (2006).

\section{Reasoning behind experimental data choice and underlying assumptions}

The presented investigation only applies to the behaviour of clay aggregates (see Fig. 1), while the behaviour of most compacted clays is influenced by its macrostructure and is thus more complex. For this reason, the choice of experimental data used in the evaluation was restricted.

First of all, the focus was given to the volumetric behaviour. The effective stress framework must also be capable of representing the response in shear; however, the shear response of compacted clay is predominantly controlled by the behaviour of macrostructure (as predicted by the double structure modelling), which is outside the scope of the present paper.

In the investigation, two main assumptions were adopted: the clay aggregate was considered to be fully saturated up to high suction levels and the aggregate response was considered to be elastic. This choice has been supported by investigation of various authors in the past. 
Full-saturation of aggregates even at high suction has been suggested by Martin (1960), Gens and Alonso (1992), Alonso et al. (1999), Yong (1999b) and Fityus and Buzzi (2008). For example, Fityus and Buzzi (2008) have shown water retention curves of the natural clay samples indicating ir entry value of suction approximately $10 \mathrm{MPa}$, while they argue that the microstructural units (aggregates) could theoretically resist air entry up to suctions as great as 80 to $100 \mathrm{MPa}$. The upper limit of $100 \mathrm{MPa}$ corresponds to the tensile strength of water at $20^{\circ} \mathrm{C}$ calculated using the van der Waals equation (Marinho et al. 2008). Another argument supporting full aggregate saturation is given in Delage et al. (1998), who observed that the total volume change of the soil specimen during unconfined swelling is exactly equal to the water volume sucked into the sample. If the aggregates were in the unsaturated state, then decrease of matric suction would imply increase of their degree of saturation (following their water retention curve). The pores which were air-filled initially would saturate with water, and thus the total aggregate volume change would be smaller than the volume of water sucked into the sample.

Referring to the reversibility of the mechanical response, Madsen and Müller-Vonmoos (1989) and Pusch (2006) noted that the contraction-expansion process of smectite-rich clays is an almost reversible process since it depends primarily on the hydration potential. Reversibility of the aggregate behaviour has also been suggested by Callaghan and Ottewill (1974), Delage et al. (1998), Tripathy et al. (2002), Cui et al. (2002) and Rao et al. (2004). This conclusion is not general and depends on the particular clay mineralogy. While montmorillonitic aggregates generally show a reversible response, the deformation of illitic clays is not solely governed by diffuse double layer phenomena (Pusch 2006) and the response is to some degree irreversible.

\section{Original experimental data}

Unconfined water retention curve The water retention curve (WRC), in unconfined conditions, shows the relationship between the water content and suction at zero net stress. Experimental water retention curves are available for FEBEX, Kunigel V1, MX-80 and FoCa7 bentonites; see Fig. 4. Wetting (that is, "unloading") branches of the water retention curves were evaluated, for consistency with the mechanical unloading tests.

In the data evaluation, the findings by Villar and Lloret (2004), Jacinto et al. (2009) and Romero et al. (2011) were adopted. They observed that the water retention curve is in the higher suction range $\left(s_{t}>2 \mathrm{MPa}\right.$ for Boom clay by Romero et al. 2011) independent of the global dry density $\rho_{d}^{t}$ (solid mass over total soil volume). Della Vecchia et al. (2013) interpreted this finding in the following way: In this suction range the macrostructure is 


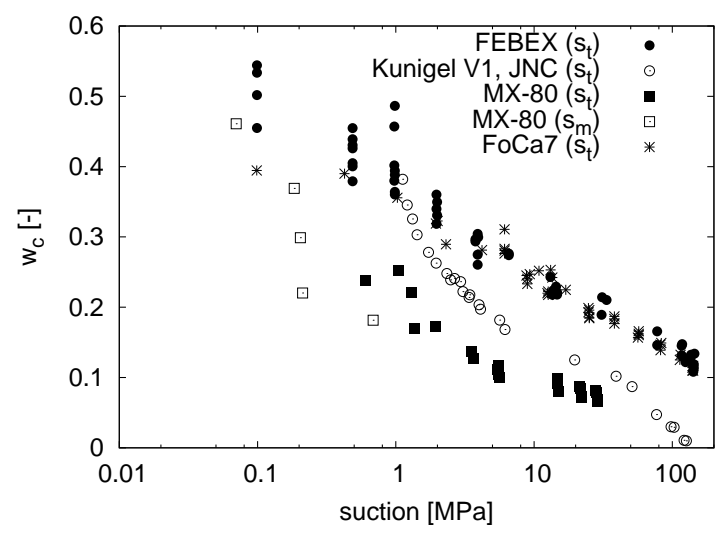

Figure 4: Wetting branches of water retention curves of soils from original experimental data. $w_{c}$ is the gravimetric water content.

dry, and all water contained within the specimen is present within the clay aggregates. The fact that the water retention curve is (in the higher suction range) independent of $\rho_{d}^{t}$ means that the dry density of aggregates is independent of the compaction effort adopted in sample preparation (compaction affects the macropores; recall also that the aggregate response is primarily reversible).

With regard to the saturation of aggregates, an approach adopted by Mašín (2013) was followed. He assumed that the aggregates are saturated, and attributed any water content changes in the WRC measurements to aggregate dry density changes (void ratio), rather than to changes in their degree of saturation. With this assumption, together with the assumption of dry macrostructure, the global water content $w_{c}$ can be used to calculate the dry density of aggregates $\rho_{d}$ (solid mass over volume of aggregates) and the void ratio $e$ (volume of pores within aggregates over volume of aggregates) using the following relationships:

$$
\rho_{d}=\frac{G_{s}}{G_{s} w_{c}+1} \rho_{w} \quad e=G_{s} w_{c}
$$

where $G_{s}=\rho_{s} / \rho_{w}$ is solid specific gravity, $w_{c}=m_{w} / m_{s}$ is the gravimetric water content, and $m_{s}, m_{w}, \rho_{s}$ and $\rho_{w}$ are solid and water masses and densities respectively. As noted above, Eq. (7) could theoretically be valid up to the suctions of 80 to $100 \mathrm{MPa}$. In the evaluation of the experimental data, $G_{s}=2.7$ (Mitchell and Soga 2005) and $\rho_{w}=1000 \mathrm{~kg} / \mathrm{m}^{3}$ has been adopted throughout. A simplification has thus been introduced here, since the intercrystalline water may have a higher density than the equilibrium solution and the double layer water (Martin 1960, Hueckel 1992a, Yan et al. 1996, Mitchell and Soga 2005, Jacinto et al. 2012). For example, Jacinto et al. (2012) estimated the average water density for MX-80 bentonite 
to vary between $\rho_{w}=1080 \mathrm{~kg} / \mathrm{m}^{3}$ (for suction of $1 \mathrm{MPa}$ ) and $\rho_{w}=1160 \mathrm{~kg} / \mathrm{m}^{3}$ (for suction of $100 \mathrm{MPa})$. Any uncertainty in $G_{s}$ was also inglected. It should be noted that an error in the $\rho_{d}$ evaluation due to $G_{s}$ uncertainty and $\rho_{w}$ variation, is in the order of $10 \%$ to $20 \%$, which is less than the data scatter typically observed in the experiments (see the data evaluation in Figs. 9 and 10).

Under the assumption of full aggregate saturation, matric suction is equal to the negative pore water pressure, and the Terzaghi's effective mean stress $p^{\prime}$ is equal to the matric suction $s_{m}$. In the higher suction range, suction in the experiments is imposed by controlling the relative humidity of the system, which represents the total suction $s_{t}$. In the following, matric suction has been estimated from the experimental data using an approximation $s_{m}=s_{t}-s_{\pi 0}$. A single value of $s_{\pi 0}=0.41 \mathrm{MPa}$ has been adopted in evaluating all the available data. This value was obtained by Romero (1999) as the osmotic suction of pore water of compacted Boom clay prepared by mixing it with demineralised water. As the osmotic suction is reported to increase with increasing matric suction due to the higher proportion of double layer and equilibrium solution volumes (Krahn and Fredlund 1972, Mata et al. 2002, Miller and Nelson 2006, Stenke et al. 2006 and Thyagaraj and Rao 2010), the values for the effective stresses obtained represent an upper bound for the exact values.

Confined wetting (swelling pressure) tests The confined wetting test (swelling pressure test) is an important method for characterising the swelling properties of compacted soils, as it resembles the situation encountered in engineered barriers, where the bentonite hydrates under confined conditions. The experiments are typically performed in the ascompacted state at total suctions corresponding to the relative humidity in the laboratory. The soil is soaked, and the resultant total stresses due to confined wetting are measured. Swelling pressure test results are available for FEBEX, MX-80, Bavaria, Avonseal, FoCa7, Kunigel V1, Volclay, Kunibond and Neokunibond bentonites (Fig. 5).

Figure 5 shows the swelling pressure test results plotted in the plane of the initial global dry density $\rho_{d 0}^{t}$ (solid mass over total soil volume at the beginning of the test) with respect to the final swelling pressure at zero matric suction. In the initial as-compacted state, the global dry density does not represent the dry density of aggregates due to the presence of macropores. After saturation, however, experimental observations by different authors suggest that more uniform pore size distribution is attained. For example, Monroy et al. (2010) studied the development of pore size distribution with wetting of a statically dry-of-optimum compacted London clay using mercury intrusion porosimetry. Initially, the porosity distribution was bi-modal, with clearly distinguishable macropores (inter-aggregate pores) and inter-particle 

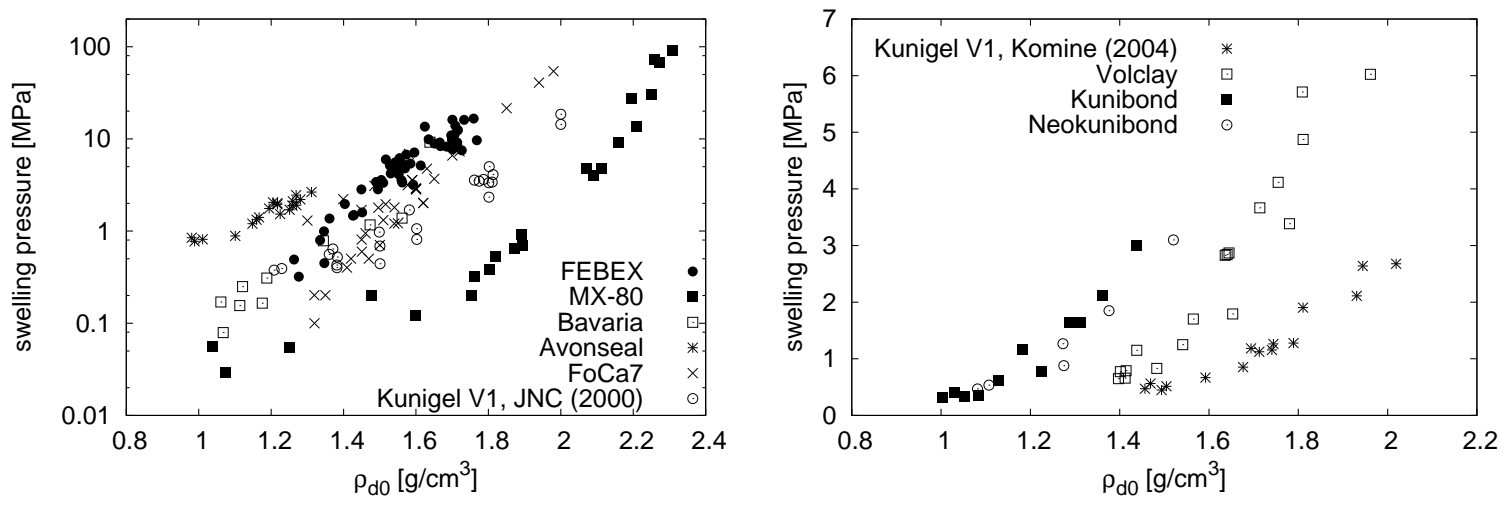

Figure 5: Swelling pressure tests from original experimental data. (a) various sources, (b) data by Komine (2004).

pores (intra-aggregate pores). As the suction decreased, the inter-particle porosity increased, implying swelling of the aggregates. The macroporosity, however, remained largely unaltered. In the last wetting step (wetting from a suction of $40 \mathrm{kPa}$ to $0 \mathrm{kPa}$ ), however, the porosity became mono-modal, and the aggregated structure was no longer clearly observable. Therefore at full saturation, the global dry density can be assumed to represent the dry density of the "aggregate". Because the global dry density is constant during the swelling pressure test, the initial global dry density represents the "aggregate" dry density at full saturation. Similar results to Monroy et al. (2010) indicating mono-modal porosity distribution at saturation were reported by Simms and Yanful (2001) (clayey till), Lloret and Villar (2007) (FEBEX bentonite) and Romero et al. (2011) (Boom clay).

From the test specification, matric suction is nil at the end of the swelling pressure test, and the swelling pressure thus represents the effective stress $p^{\prime}$ within soil specimen.

Mechanical unloading tests on saturated soil The next experiments that were evaluated were mechanical unloading tests on saturated soils or those at a constant suction. Only those experiments starting from high stress levels (of the order of tens of $\mathrm{MPa}$ ) are relevant for the data evaluation. In this case, the macroporosity is very low and the global dry density (global void ratio) represents the dry density (void ratio) of the aggregates.

The behaviour of aggregated soil during subsequent unloading can be studied with the aid of double-structure models. The model proposed by Mašín (2013) assumes the following function to represent the double structure coupling for the effective stress decrease:

$$
f_{m}=1-\left(r_{e m}\right)^{m_{c}}
$$


In Eq. (8), $f_{m}$ is the so-called double structure coupling function. $f_{m} \rightarrow 1$ implies that no macrostructural changes occur during unloading (aggregate deformation is equal to the total sample deformation), whereas $f_{m} \rightarrow 0$ implies that the aggregates occlude freely into macropores with no deformation of the macrostructure. $r_{e m}$ in Eq. (8) represents the relative void ratio $\left(r_{e m}=0\right.$ for maximum density state and $r_{e m}=1$ for the loosest packing). $m_{c}$ in Eq. (8) is a positive valued parameter.

For mechanical unloading from the dense initial state, the model (Eq. (8)) implies $f_{m} \rightarrow 1$, that is, the aggregate deformation is equal to the total sample deformation. Approximate validity of Eq. (8) was assumed in the evaluation of the experimental data. Oedometric unloading test data at saturated conditions are available for FEBEX and Bavaria bentonites (Fig. 6a). Isotropic loading-unloading tests at extremely high cell pressures and different suctions are available for FoCa7 bentonite (Fig. 6b).

Isotropic compression results on reconstituted Avonseal bentonite were also included (Fig. 6a). Comparisons with the Avonseal data should be considered with caution, however; swelling pressure measurements were performed using samples compacted at total suctions corresponding to the relative humidity in the laboratory, whereas bentonite reconstituted in a saturated state was used in the isotropic compression tests. Reconstitution is likely to introduce changes into soil structure and its mechanical response (Fearon and Coop 2000).
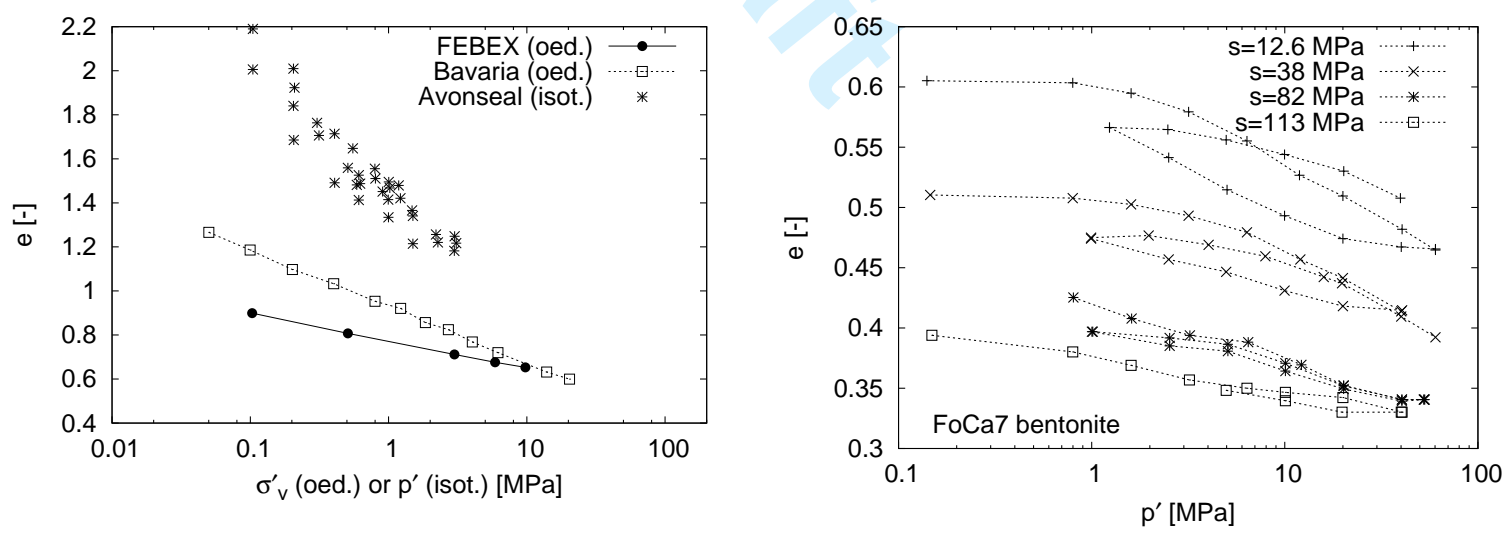

Figure 6: Mechanical unloading and compression tests; original experimental data. (a) different sources, $s=0$; (b) isotropic tests on FoCa7 bentonite at different suctions.

Evaluation of oedometric unloading tests (that is, tests on FEBEX and Bavaria bentonites) is complicated by the fact that the measured vertical stress does not represent the mean effective stress. For the purpose of the evaluation, the value of $K_{0}$ (ratio of horizontal and vertical effective stresses) has been estimated using the Mayne and Kulhawy (1982) empirical 
relationship

$$
K_{0}=\left(1-\sin \varphi_{c}\right) \mathrm{OCR}^{\sin \varphi_{c}}
$$

where OCR denotes the overconsolidation ratio, calculated as the ratio of initial vertical stress of the unloading experiment (equal to the maximum vertical stress to which the soil was subjected) and current vertical stress $\sigma_{v}^{\prime} \cdot \varphi_{c}=25^{\circ}$, as reported for FEBEX bentonite by Gens et al. (2009), was used in the $K_{0}$ estimation using Eq. (9). The value of $\varphi_{c}$ was not available for Bavaria bentonite. In the $K_{0}$ estimation, FEBEX bentonite value for Bavaria bentonite was used; this should not introduce substantial errors due to the similar composition of the two bentonite types. The effective mean stress can be calculated from the known vertical stress and $K_{0}$ estimated using Eq. (9) by

$$
p^{\prime}=\sigma_{v}^{\prime} \frac{1+2 K_{0}}{3}
$$

Test data on Avonseal and FoCa7 clays are at isotropic conditions, where the mean stress is measured directly and thus an estimation of $K_{0}$ is not required.

Wetting under constant load tests The last type of experiments evaluated are wettinginduced swelling tests at a constant vertical load. The tests were performed under oedometric conditions on unsaturated soil samples compacted to different known initial global dry densities. The soil was then soaked and left to swell under constant vertical load. The experimental data relate the swelling strain $\epsilon_{s}$ to the sample initial global dry density. Data are available for FEBEX, Kunigel V1, Volclay, Kunibond and Neokunibond bentonites (Fig. 7).

The experimental data were evaluated in the following way: Firstly, it was assumed that at saturation the pore space distribution is mono-modal by the end of the test, similar to the confined swelling pressure tests. The final soil dry density $\rho_{d}$ thus represents the aggregate dry density at full saturation. The experimental sources, however, are normally presented in terms of the initial global dry density vs. vertical swelling strain. The final soil dry density can be calculated from the initial global dry density $\rho_{d 0}$ and swelling strain $\epsilon_{s}$ using a simple relationship $\rho_{d}=\rho_{d 0} /\left(1+\epsilon_{s}\right)$ (note that under oedometric conditions the measured vertical strain equals the volume strain). As in the case of the oedometric unloading tests, the oedometric conditions imply development of horizontal stresses, which are not measured. However, in this case since the initial stress state does not correspond to the oedometric normally consolidated conditions, $K_{0}$ cannot be estimated using Eq. (9). In the evaluation, a fixed value of $K_{0}=1.5$ was adopted and the mean stress was calculated using Eq. (10), and also investigated the sensitivity of the results on the selected $K_{0}$ value. The relative 

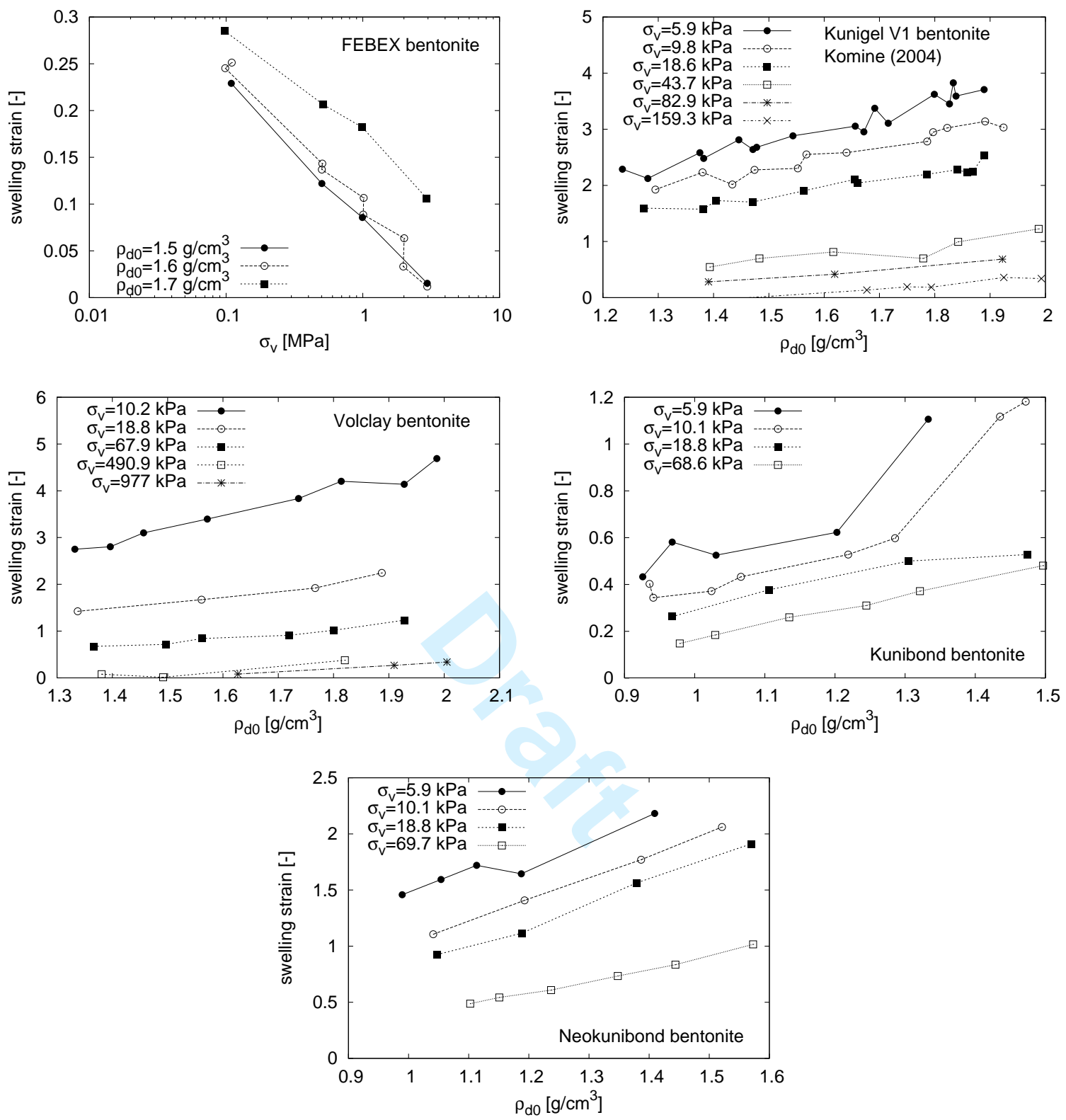

Figure 7: Swelling under constant load, original experimental data.

insensitivity of the results to the $K_{0}$ value assumed in evaluation of the swelling during constant load tests is shown in Fig. 8. 


\section{Unified interpretation of the experimental results}

All the results of the above described experiments have been plotted in the space of mean effective stress $p^{\prime}$ vs. aggregate dry density $\rho_{d}$. Results for all soils and test types are given in Figs. 9 and 10. It can be seen that the data form distinct bands in the $p^{\prime}$ vs. $\rho_{d}$ space, although it should be pointed out that the data themselves are relatively scattered. These results are in agreement with findings by Johannesson et al. (1999) and Dueck et al. (2010), who observed equivalence between the swelling pressure and water retention behaviour evaluated under the assumption of full saturation of the aggregate. It has also been discussed in terms of the continuum thermodynamic model by Dueck and Börgesson (2007).

The fact that the data reveal a unique relationship between the mean effective stress $p^{\prime}$ and aggregate dry density $\rho_{d}$ has the following consequence. First of all, assumptions supported by investigations of various authors need to be recalled: the aggregate response is primarily reversible, and the aggregates may be considered as saturated up to very high values of suction. The evaluated experiments involve both tests with suction variability at constant total stress and constant suction tests with variable total stress. The unique representation in the $p^{\prime}$ vs. $\rho_{d}$ plane means that the soil deformation depends solely on the mean effective stress, which is consistent with Terzaghi's effective stress definition.

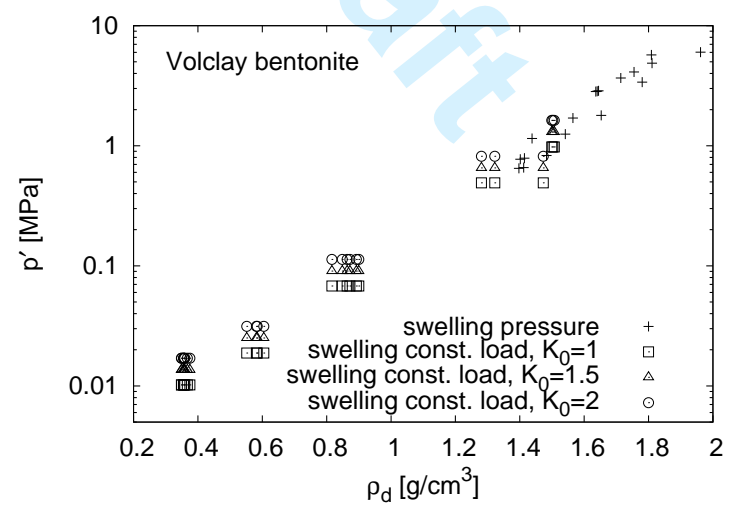

Figure 8: Experimental data on Volclay re-plotted in the $\rho_{d}$ vs. $p^{\prime}$ space; sensitivity of results to the assumed $K_{0}$ value in swelling under constant load tests.

To combine such a large experimental database into a single-purpose work required obviously a number of assumptions, which were however in the author's opinion reasonably justified by recalling investigations by various authors. Specific assumptions and their possible effect on conclusions may be studied in a more detailed work later. The most important ones were full saturation of aggregates and aggregate response reversibilty. In addition, we assumed that: 

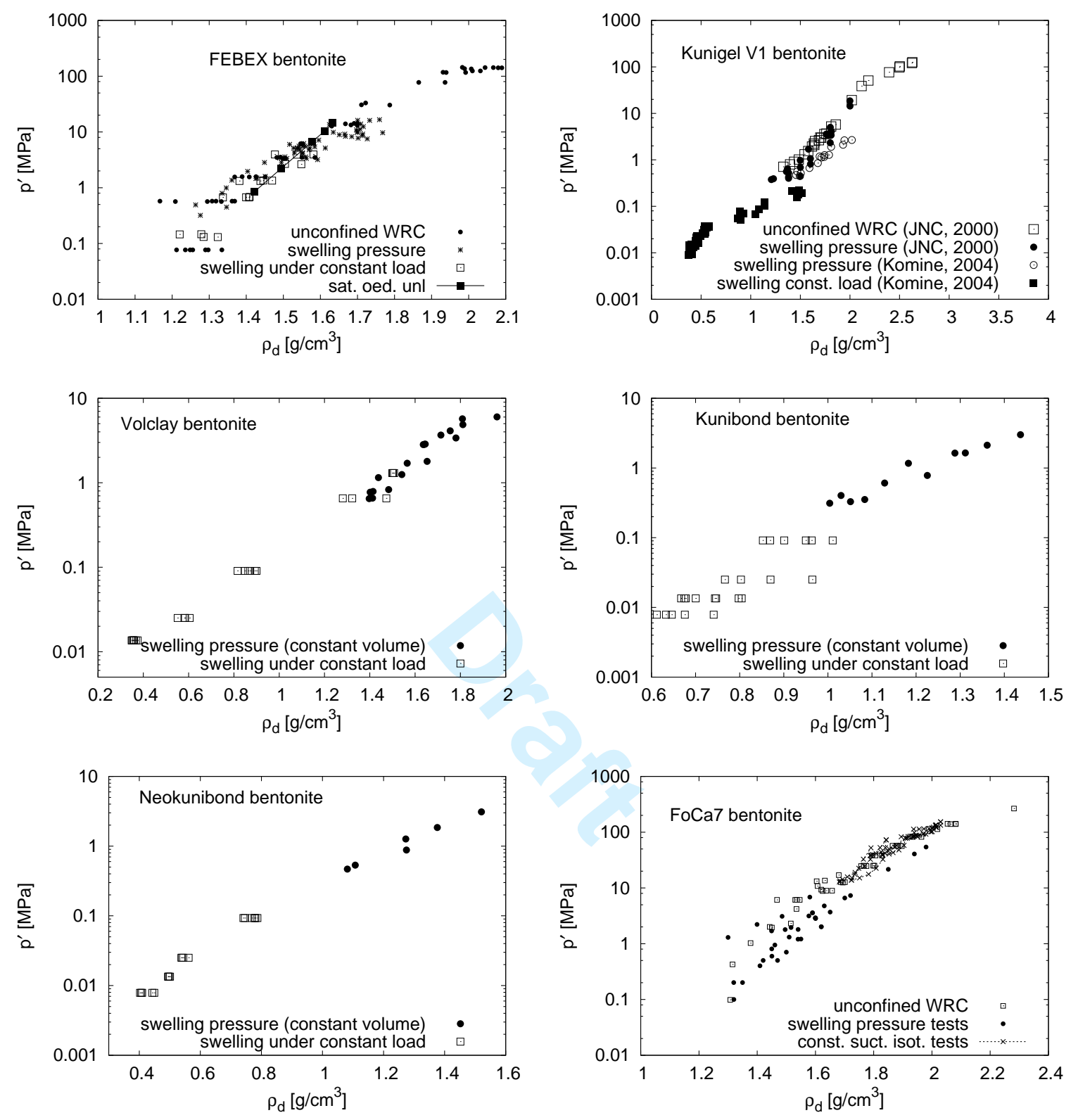

Figure 9: Experimental data re-plotted in the $\rho_{d}$ vs. $p^{\prime}$ space, part 1.

different experiment types performed in a single soil mechanics laboratory were consistent with respect to each other; macrovoids were dry in water retention tests at higher matric suctions (approximately $s_{t}>2 \mathrm{MPa}$ ); density of water was assumed to be constant $\left(\rho_{w}=\right.$ $1000 \mathrm{~kg} / \mathrm{m}^{3}$ ); osmotic suction was assumed to be constant throughout the water retention experiment $\left(s_{\pi}=0.41 \mathrm{MPa}\right)$; void distribution was monomodal at the end of swelling pressure 

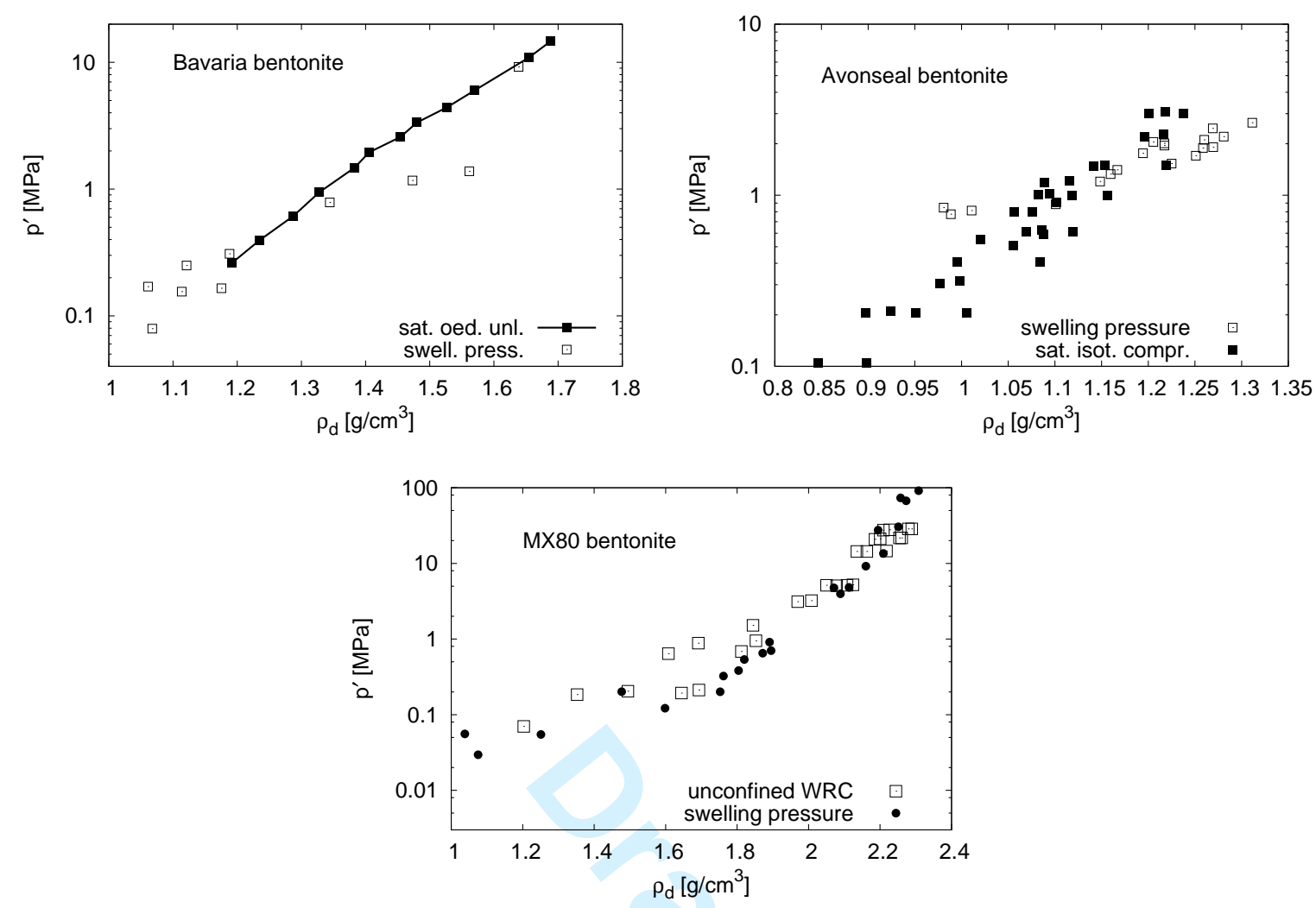

Figure 10: Experimental data re-plotted in the $\rho_{d}$ vs. $p^{\prime}$ space, part 2.

tests and wetting under constant load tests; samples for mechanical unloading tests loaded to tens of MPa had initially closed macrovoids; macrovoids in these samples did not open up in unloading; $K_{0}$ in oedometric unloading tests could be represented using Mayne and Kulhawy (1982) formula; $K_{0}$ in wetting under constant load tests was assumed to be equal to 1.5 (the relatively minor effect of this relatively strict assumption was investigated in a parametric study).

\section{Concluding remarks}

In this paper, phenomena occurring between individual clay particles and layers in bentonite soils at the molecular scale were analysed. The work by Derjaugin et al. (1987) implies that the pressure normal to the clay particle predicted by the diffuse double layer theory is equal to the sum of disjoining pressure and hydrostatic pressure in equilibrium solution. This indicates that the Terzaghi effective stress principle is adequate to describe clay behaviour at 
the aggregate level, with the limits coinciding with the limits of validity of the diffuse double layer theory.

To support these conclusions, data were analysed from an extensive experimental database on compacted smectitic clays from the literature. The results are scattered, but there appears to be an interestingly unique relationship between the aggregate dry density (void ratio) and the mean Terzaghi's effective stress (quantified under the assumption of aggregate saturation), for both variable suction and variable total stress experiments. In combination with the assumption of aggregate response reversibility, the experiments support the validity of using the Terzaghi's effective stress to predict the aggregate volumetric deformation. It was also pointed out that the proposed approach was limitted to inter-particle distances larger than approx. $1.5 \mathrm{~nm}$ (dry densities up to $2.2 \mathrm{~g} / \mathrm{cm}^{3}$ ). At smaller distances, the Eq. (2), upon which the developments proposed here are based, becomes inaccurate. The experimental data set given in Bucher and Müller-Vonmoos (1989) is a possible manifestation of this limitation.

\section{Acknowledgment}

Financial support by the research grants 15-05935S and 14-32105S of the Czech Science Foundation is greatly appreciated. The first author further appreciates the Australian Research Council support and a Visiting Fellow appointment in the School of Civil and Environmental Engineering of The University of New South Wales, Sydney, where this paper originated. 


\section{Notation}

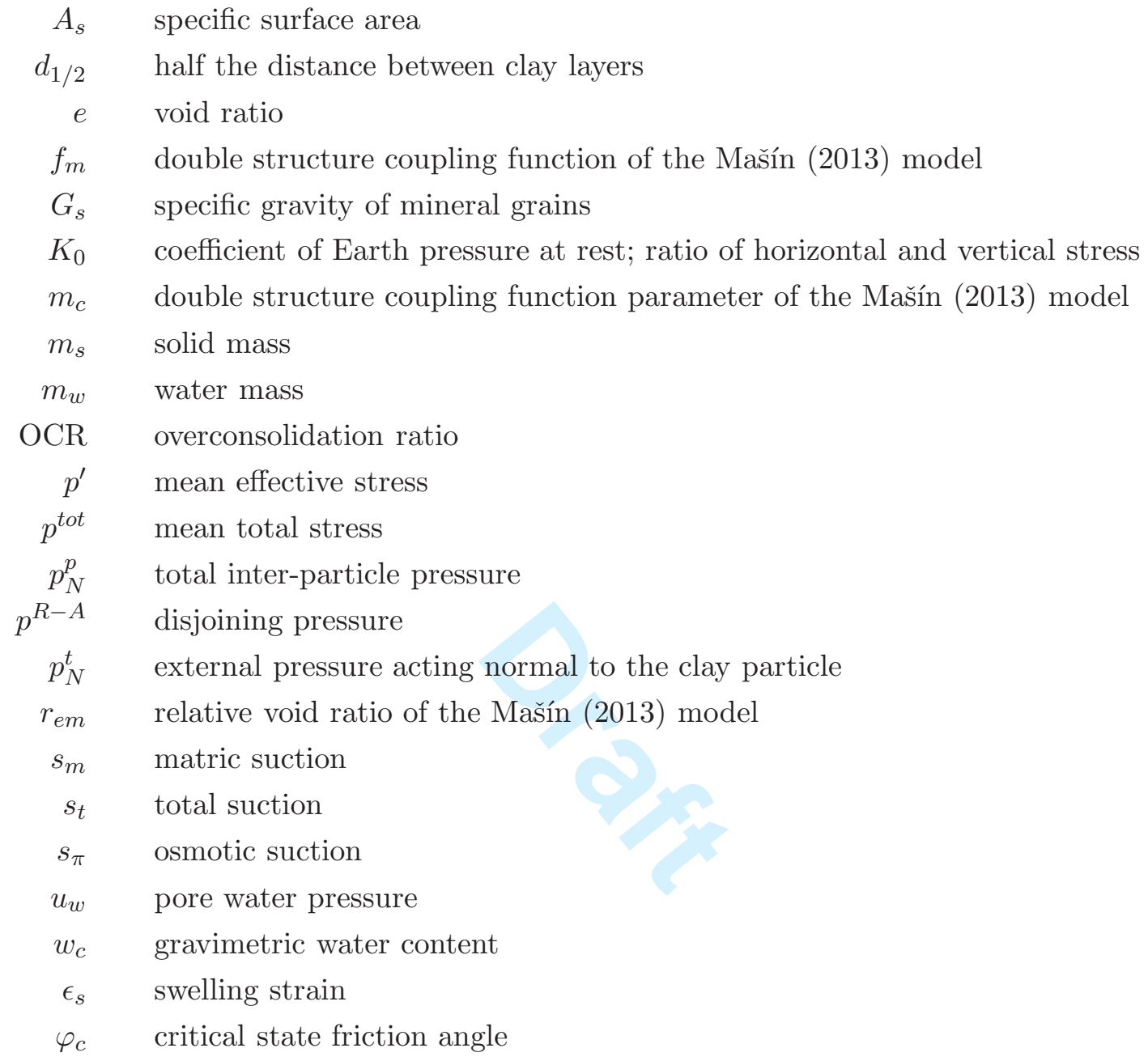




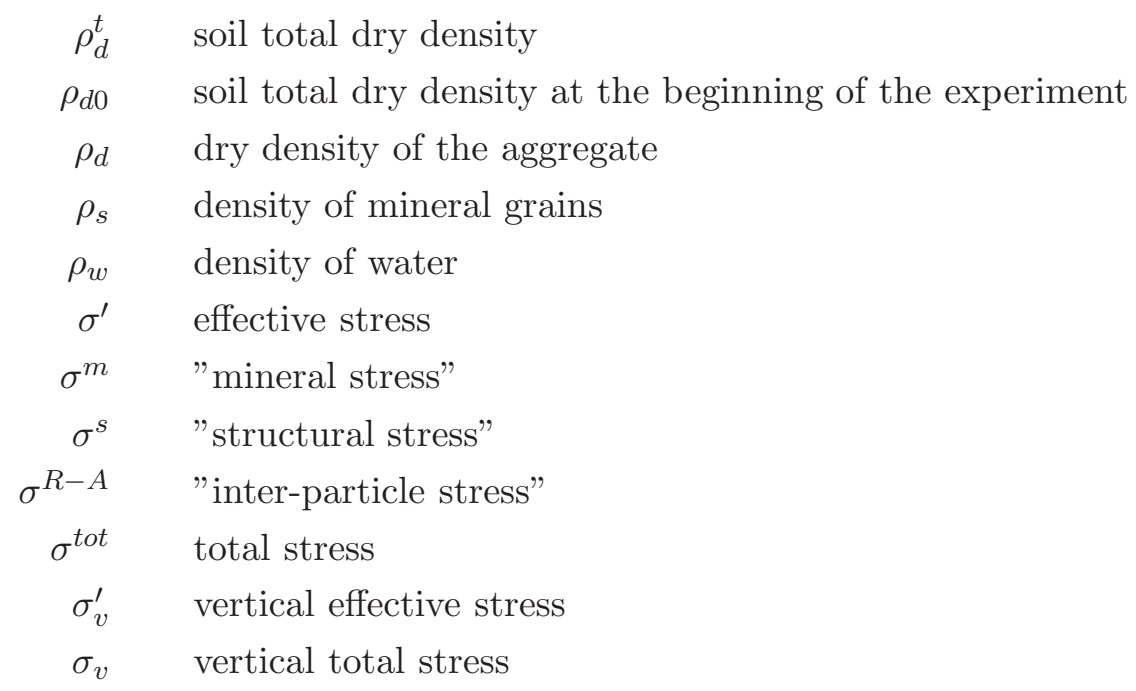

\section{References}

Allam, M. M. and A. Sridharan (1984). The shearing resistance of saturated clays. Géotechnique 34(1), 119-122.

Alonso, E. E., J. Vaunat, and A. Gens (1999). Modelling the mechanical behaviour of expansive clays. Engineering Geology 54, 173-183.

Aylmore, L. A. G., I. D. Sills, and J. P. Quirk (1970). Surface area of homoionic illite and montmorillonite clay minerals as measured by the sorption of nitrogen and carbon dioxide. Clays and Clay Minerals 18, 91-96.

Baille, W., S. Tripathy, and T. Schanz (2010). Swelling pressures and one-dimensional compressibility behaviour of bentonite at large pressures. Applied Clay Science 48, $324-333$.

Balasubramonian, B. I. (1972). Swelling of compaction shale. Ph. D. thesis, University of Alberta, Edmonton.

Bennethum, L. S., M. A. Murad, and J. H. Cushman (1997). Modified darcy's law, fick's law, and terzaghi's effective stress principle for swelling clay soils. Technical report, University of Colorado at Denver, Center for Computational Mathematics.

Biot, M. A. (1941). General theory of three-dimmensional consolidation. Journal of Applied Physics 12, 155-164.

Bolt, G. H. (1956). Physico-chemical analysis of the compressibility of pure clays. Géotechnique 6, 86-93. 
Bucher, F. and M. Müller-Vonmoos (1989). Bentonite as a containment barrier for the disposal of highly radioactive wastes. Applied Clay Science 4, 157-177.

Buzzi, O. (2010). On the use of dimensional analysis to predict swelling strain. Engineering Geology 116, 149-156.

Buzzi, O., S. G. Fityus, and S. W. Sloan (2007). Proposition for a simple volume change model for expansive saturated soils. In S. Pietruszczak and G. N. Pande (Eds.), Proc. of the $10^{\text {th }}$ International Symposium on Numerical Models in Geomechanics, NUMOG $X$, pp. 99-104. Taylor \& Francis Group, London, UK.

Buzzi, O. and S. G. Giacomini, A. Fityus (2010). Towards a dimensionless description of soil swelling behaviour. Géotechnique 61(3), 271-277.

Callaghan, I. C. and R. H. Ottewill (1974). Interparticle forces in montmorillonite gels. Faraday Discuss. Chem. Soc. 57, 110-118.

Chapman, D. L. (1913). A contribution to the theory of electrocapillarity. Phil. Mag. 25, 475-481.

Cui, Y. J., M. Yahia-Aissa, and P. Delage (2002). A model for the volume change behavior of heavily compacted swelling clays. Engineering Geology 64, 233-250.

Cushman, J. H. (1990). Molecular scale lubrication. Nature 347, 227-228.

Delage, P., M. D. Howat, and Y. J. Cui (1998). The relationship between suction and swelling properties in a heavily compacted unsaturated clay. Engineering Geology 50, $31-48$.

Della Vecchia, G., C. Jommi, and E. Romero (2013). A fully coupled elastic-plastic hydromechanical model for compacted soils accounting for clay activity. International Journal for Numerical and Analytical Methods in Geomechanics 37, 503-535.

Derjaugin, B. V., N. V. Churaev, and V. M. Muller (1987). Surface Forces, $1^{\text {st }}$ ed. Consult. Bur., New York.

Devineau, K., I. Bihannic, L. Michot, F. Villiéras, F. Masrouri, O. Cuisinier, G. Fragneto, and N. Michau (2006). In situ neutron diffraction analysis of the influence of geometric confinement on crystalline swelling of montmorillonite. Applied Clay Science 31, 76-84.

Dueck, A. and L. Börgesson (2007). Model suggested for an important part of the hydromechanical behaviour of a water unsaturated bentonite. Engineering Geology 92, 160169 .

Dueck, A., L. Börgesson, and L.-E. Johannesson (2010). Stress-strain relation of bentonite at undrained shear, laboratory tests to investigate the influence of material composition 
and test technique. Technical Report No. TR-10-32, SKB, Swedish Nuclear Fuel and Waste Management Co.

Emerson, W. W. (1962). The swelling of Ca-montmorillonite due to water absorption I. water uptake in the vapour phase. Journal of Soil Science 13(1), 31-39.

Fam, M. and J. C. Santamarina (1996). Coupled diffusion-fabric-flow phenomena: an effective stress analysis. Canadian Geotechnical Journal 33, 512-522.

Farmer, V. C. and J. D. Russell (1971). Interlayer complexes in layer silicates. The structure of water in lamellar ionic solutions. Trans. Faraday Soc. 67, 2737-2749.

Fearon, R. and M. R. Coop (2000). Reconstitution: what makes an appropriate reference material? Géotechnique 50(4), 471-477.

Ferrage, E., B. Lanson, B. A. Sakharov, and V. A. Drits (2005). Investigation of smectite hydration properties by modeling experimental X-ray diffraction patterns: Part I. Montmorillonite hydration properties. American Mineralogist 90, 1358-1374.

Fityus, S. and O. Buzzi (2008). The place of expansive clays in the framework of unsaturated soil mechanics. Applied Clay Science 43(2), 150-155.

Gee, M. L., P. M. McGuiggan, J. N. Israelachvili, and A. M. Homola (1990). Liquid to solidlike transitions of molecuraly thin films under shear. The Journal of Chemical Physics 93, 1895-1906.

Gens, A. and E. Alonso (1992). A framework for the behaviour of unsaturated expansive clays. Canadian Geotechnical Journal 29, 1013-1032.

Gens, A., M. Sánchez, L. D. N. Guimaráes, E. E. Alonso, A. Lloret, S. Olivella, M. V. Villar, and F. Huertas (2009). A full-scale in situ heating test for high-level nuclear waste disposal: observations, analysis and interpretation. Géotechnique 59(4), 377-399.

Gonçalvès, J., P. Rousseau-Gueutin, G. de Marsily, P. Costenza, and S. Violette (2010). What is the significance of pore pressure in a saturated shale layer? Water Resources Research 46, W04514.

Gouy, G. (1910). Sur la constitution de la charge à la surface d'un électrolyte. J. Phys. 9, $457-468$.

Graham, J., F. Saadat, M. N. Gray, D. A. Dixon, and Q.-Y. Zhang (1989). Strength and volume change behaviour of a sand-bentonite mixture. Canadian Geotechnical Journal 26, 292-305.

Hassanizadeh, M. and W. G. Gray (1979). General conservation equations for multi-phase systems: 1. Averaging procedure. Advances in Water Resources 2(3), 131-144. 
Herbert, H.-J. and H. C. Moog (2000). Modelling of saturation and swelling effects in clays under different saline conditions. In Eurosafe Forum 2000, Seminar 4: Waste management.

Homola, A. M., J. N. Israelachvili, M. L. Gee, and P. M. McGuiggan (1989). Measurement of and relation between the adhesion and friction of two surfaces separated by molecuraly thin liquid films. Journal of Tribology 111, 675-682.

Hueckel, T. (1992a). On effective stress concepts and deformation in clays subjected to environmental loads: Discussion. Canadian Geotechnical Journal 29, 1120-1125.

Hueckel, T. (1992b). Water-mineral interaction in hygromechanics of clays exposed to environmental loads: a mixture theory approach. Canadian Geotechnical Journal 29, 1071-1086.

Israelachvili, J. N., P. M. McGuiggan, and A. M. Homola (1988). Dynamic properties of molecuraly thin liquid films. Science 240(4849), 189-191.

Israelachvili, J. N. and R. M. Pashley (1983). Molecular layering of water at surfaces and origin of repulsive hydration forces. Nature 306, 249-250.

Jacinto, A. C., M. V. Villar, R. Gómez-Espina, and A. Ledesma (2009). Adaptation of the van Genuchten expression to the effects of temperature and density for compacted bentonites. Applied Clay Science 42, 575-582.

Jacinto, A. C., M. V. Villar, and A. Ledesma (2012). Influence of water density on the water-retention curve of expansive clays. Géotechnique 62(8), 657-667.

JNC (2000). H12: Project to establish the scientific and technical basis for HLW disposal in Japan. Supporting report 2. Repository design and engineering technology. Technical Report JNC TN1410 2000-03, JNC, Japan Nuclear Cycle Development Institute.

Johannesson, L.-E., L. Börgesson, and T. Sandén (1999). Äspö hard rock laboratory. Backfill materials based on crushed rock (part 2). Geotechnical properties determined in laboratory. Technical Report No. IPR-99-23, SKB, Swedish Nuclear Fuel and Waste Management Co.

Kaczmarek, M. and T. Hueckel (1998). Chemo-mechanical consolidation of clays: analytical solution for linearised one-dimensional problem. Transport in Porous Media 32, 49-74.

Karnland, O., S. Olsson, and U. Nilsson (2006). Mineralogy and sealing properties of various bentonites and smectite-rich clay materials. Technical Report No. TR-06-30, SKB, Swedish Nuclear Fuel and Waste Management Co. 
Katti, D. R., M. I. Matar, K. S. Katti, and P. M. Amarasinghe (2009). Multiscale modelling of swelling clays: A computational and experimental approach. KSCE Journal of Civil Engineering 13(4), 243-255.

Komine, H. (2004). Simplified evaluation for swelling characteristics of bentonites. Engineering Geology 71, 265-279.

Komine, H. and N. Ogata (1999). Prediction method for swelling characteristics of bentonite for nuclear waste disposal. In Proc. of the th International Conference on Radioactive Waste Management and Environmental Remediation (CD-ROM).

Komine, H. and N. Ogata (2004). Predicting swelling characteristics of bentonites. Journal of Geotechnical and Geoenvironmental Engineering ASCE 130(8), 818-829.

Krahn, J. and D. G. Fredlund (1972). On total, matric and osmotic suction. Soil Science $114(5), 339-348$.

Lambe, T. W. (1958). The engineering behaviour of compacted clay. Journal of Soil Mechanics 8 Foundation Division, ASCE 84(2), 1655/1-35.

Lambe, T. W. (1960). A mechanistic picture of shear strength in a clay. In Proc. ASCE Conference on Shear Strength of Cohesive Soils, Boulder, Colorado, pp. 503-532.

Lempinen, A. (2011). Coupling swelling and water retention processes in compacted bentonite. Chemical Product and Process Modelling 6(1).

Leonards, G. (1962). discussion of 'Limitations to the use of effective stresses in partly saturated soils'. Géotechnique 12, 354-355.

Liu, L. (2013). Prediction of swelling pressures of different types of bentonite in dilute solutions. Colloids and Surfaces A: Physicochemical and Engineering Aspects 434, 303318.

Lloret, A. and M. V. Villar (2007). Advances on the knowledge of the thermo-hydromechanical behaviour of heavily compacted "FEBEX" bentonite. Physics and Chemistry of the Earth 32, 701-715.

Loret, B., T. Hueckel, and A. Gajo (2002). Chemo-mechanical coupling in saturated porous media: elastic-plastic behaviour of homoionic expansive clays. International Journal of Solids and Structures 39, 2773-2806.

Low, P. F. (1979). The swelling of clay. I: basic concepts and epmpirical equations. Soil Science Society of America Journal 43, 473-481.

Low, P. F. and D. M. Anderson (1958). Osmotic pressure equation for determining thermodynamic properties of soil water. Soil Science 86, 251-253. 
Lu, N. L. and W. J. Likos (2006). Suction stress characteristic curve for unsaturated soil. Journal of Geotechnical and Geoenvironmental Engineering ASCE 132(2), 131-142.

Madsen, F. T. and M. Müller-Vonmoos (1989). The swelling behaviour of clays. Applied Clay Science 4, 143-156.

Marinho, F. A. M., W. A. Take, and A. Tarantino (2008). Measurement of matric suction using tensiometric and axis translation techniques. Geotech Geol Eng 26, 615-631.

Martin, R. T. (1960). Adsorbed water on clay: a review. Clays and Clay Minerals 9(1), $28-70$.

Mata, C., E. Romero, and A. Ledesma (2002). Hydro-mechanical effects on water retention in bentonite-sand mixtures. In J. F. T. Jucá, T. M. P. de Campos, and F. A. M. Marinho (Eds.), $3^{\text {rd }}$ Int. Conference on Unsaturated Soils, Recife, Brasil, Volume 1, pp. 283-288.

Mašín, D. (2013). Double structure hydromechanical coupling formalism and a model for unsaturated expansive clays. Engineering Geology 165, 73-88.

Mayne, P. W. and F. H. Kulhawy (1982). $K_{0}-\mathrm{OCR}$ relationships in soil. In Proc. ASCE J. Geotech. Eng. Div., Volume 108, pp. 851-872.

Miller, D. J. and J. D. Nelson (2006). Osmotic suction in unsaturated soil mechanics. In G. A. Miller, C. E. Zapata, S. L. Houston, and D. G. Fredlund (Eds.), $4^{t 5}$ Int. Conference on Unsaturated Soils, ASCE Geotechnical Special Publication No. 14\%, pp. 1382-1393. ASCE.

Mitchell, J. K. and K. Soga (2005). Fundamentals of soil behaviour, 3rd Edition. John Wiley \& Sons, Inc., Hoboken, New Jersey.

Monroy, R., L. Zdravković, and A. Ridley (2010). Evolution of microstructure in compacted London Clay during wetting and loading. Géotechnique 60(2), 105-119.

Morgernstern, N. M. and B. I. Balasubramonian (1980). Effects of pore fluid on the swelling of clay-shale. In Proc. $4^{\text {th }}$ Int. Conference on Expansive Soils, Denver, Colorado, pp. 190-205.

Morodome, S. and K. Kawamura (2009). Swelling behaviour of Na- and Ca- montmorillonite up to $150^{\circ} \mathrm{C}$ by in situ X-ray diffraction experiments. Clays and Clay Minerals $57(2), 150-160$.

Moyne, C. and M. A. Murad (2006). A two-scale model for coupled electro-chemomechanical phenomena and Onsager's reciprocity relations in expansive clays: I Homogenisation analysis. Transport in porous media 62, 333-380. 
Murad, M. A. and J. H. Cushman (1996). Multiscale flow and deformation in hydrophilic swelling porous media. Int. J. Engng Sci. 34(3), 313-338.

Nayak, N. V. and R. W. Christensen (1971). Swelling characteristics of compacted expansive soils. Clays and Clay Minerals 19, 251-261.

Niemunis, A., C. E. Grandas Tavera, and L. F. Prada Sarmiento (2009). Anisotropic viscohypoplasticity. Acta Geotechnica 4(4), 293-314.

Nova, R., R. Castellanza, and C. Tamagnini (2003). A constitutive model for bonded geomaterials subject to mechanical and/or chemical degradation. International Journal for Numerical and Analytical Methods in Geomechanics 27, 705-732.

Nur, A. and J. D. Byerlee (1971). An exact effective stress law for elastic deformation of rock with fluids. Journal of Geophysical Research 76(26), 6414-6419.

Oliphan, J. L. and P. F. Low (1982). The relative partial specific enthalpy of water in montmorillonite-water systems and its relation to the swelling of these systems. Journal of Colloid and Interface Science 89(2), 366-373.

Phillips, A. and S. Tripathy (2011). Swelling pressures of some initially saturated and compacted saturated bentonites. International Journal of Advanced Technology in Civil Engineering 1(1), 64-69.

Pusch, R. (1982). Mineral-water interactions and their influence on the physical behavior of highly compacted Na bentonite. Canadian Geotechnical Journal 19, 381-387.

Pusch, R. (2006). Mechanical properties of clays and clay minerals. In F. Bergaya, B. K. G. Theng, and G. Lagaly (Eds.), Handbook of Clay Science, Volume 1, pp. 247-260. Elsevier.

Rao, A. S., B. R. Phanikumar, and R. S. Sharma (2004). Prediction of swelling characteristics of remoulded and compacted expansive soils using free swell index. Quarterly Journal of Engineering Geology 37, 217-226.

Romero, E. (1999). Characterisation and thermo-hydro-mechanical behaviour of unsaturated Boom clay: an experimental study. Ph. D. thesis, Universitat Polytécnica di Catalunya, Barcelona, Spain.

Romero, E., G. Della Vecchia, and C. Jommi (2011). An insight into the water retention properties of compacted clayey soils. Géotechnique 61(4), 313-328.

Saiyouri, N., P. Y. Hicher, and D. Tessier (2000). Microstructural approach and transfer water modelling in highly compacted unsaturated swelling clays. Mechanics of CohesiveFrictional Materials 5, 41-60. 
Saiyouri, N., D. Tessier, and P. Y. Hicher (2004). Experimental study of swelling in unsaturated compacted clays. Clay Minerals 39, 469-479.

Sánchez, M., A. Gens, and L. Do Nascimento Guimarães (2005). A double structure generalised plasticity model for expansive materials. International Journal for Numerical and Analytical Methods in Geomechanics 29, 751-787.

Schoen, M., C. L. Rhykerd, D. J. Diestler, and J. H. Cushman (1989). Shear forces in molecularly thin films. Science 245(4923), 1223-1225.

Simms, P. H. and E. K. Yanful (2001). Measurement and estimation of pore shrinkage and pore distribution in a clayey till during soil-water-characteristic curve tests. Canadian Geotechnical Journal 38, 741-754.

Skempton, A. W. (1960). Significance of Terzaghi's concept of effective stress. In L. Bjerrum, A. Casagrande, R. B. Peck, and A. W. Skempton (Eds.), From theory to practice in soil mechanics, pp. 42-53. Wiley, New York.

Smith, D. W., G. A. Narsilio, and P. Pivonka (2009). Numerical particle-scale study of swelling pressure in clays. KSCE Journal of Civil Engineering 13(4), 273-279.

Sposito, G. (1972). Thermodynamics of swelling clay-water systems. Soil Science 114, 243249.

Sridharan, A. and D. Choudhury (2002). Swelling pressure of sodium montmorillonites. Géotechnique 52(6), 459-462.

Sridharan, A. and M. S. Jayadeva (1982). Double layer theory and compressibility of clays. Géotechnique 32(2), 133-144.

Sridharan, A. and G. Venkatappa Rao (1973). Mechanisms controlling volume change of saturated clays and the role of the effective stress concept. Géotechnique 23(3), 359382.

Sridharan, A. and G. Venkatappa Rao (1979). Shear strength behaviour of saturated clays and the role of effective stress concept. Géotechnique 29(2), 177-193.

Stenke, F., D. G. Toll, and D. Gallipoli (2006). Comparison of water retention curves for clayey soils using different measurement techniques. In G. A. Miller, C. E. Zapata, S. L. Houston, and D. G. Fredlund (Eds.), $4^{t 5}$ Int. Conference on Unsaturated Soils, ASCE Geotechnical Special Publication No. 147, pp. 1451-1461. ASCE.

Terzaghi, K. (1936). The shearing resistance of saturated soils and the angle between the planes of shear. In International Conference on Soil Mechanics and Foundation Engineering, pp. 54-56. Harvard University Press: Cambridge, MA. 
Thomas, H. R. and P. J. Cleall (1999). Inclusion of expansive clay behaviour in coupled thermo hydraulic mechanical models. Engineering Geology 54, 93-108.

Thyagaraj, T. and S. M. Rao (2010). Influence of osmotic suction on the soil-water characteristic curves of compacted expansive clay. Journal of Geotechnical and Geoenvironmental Engineering ASCE 136(12), 1695-1702.

Tripathy, S., A. Sridharan, and T. Schanz (2004). Swelling pressures of compacted bentonites from diffuse double layer theory. Canadian Geotechnical Journal 41, 437-450.

Tripathy, S., K. S. Subba Rao, and D. G. Fredlund (2002). Water content - void ratio swell-shrink paths of compacted expansive soils. Canadian Geotechnical Journal 39, 938-959.

Van Geet, M., W. Bastiaens, G. Volckaert, E. Weetjens, X. Sillen, N. Maes, C. Imbert, P. Billaud, G. Touzé, M. Filippi, F. Plas, M. V. Villar, M. García-Gutierrez, M. Mingarro, A. Gens, and B. Vallejan (2009). RESEAL II. A large-scale in situ demonstration test for repository sealing in an argillaceous host rock - Phase II. Technical Report No. EUR 24161 EN, Europpean Comission, Contract No. FIKW-CT-2000-00010.

Villar, M. V. (2002). Thermo-hydro-mechanical characterisation of a bentonite from Cabo de Gata. A study applied to the use of bentonite as sealing material in high level radioactive waste repositories. Publicatión Técnica ENRESA 01/2002, Madrid, 258 pp.

Villar, M. V. (2007). Water retention of two natural compacted bentonites. Clays and Clay Minerals 55(3), 311-322.

Villar, M. V. and A. Lloret (2004). Influence of temperature on the hydro-mechanical behaviour of a compacted bentonite. Applied Clay Science 26, 337-350.

Warkentin, B. P. and R. K. Schofield (1958). Swelling pressures of dilute Namontmorillonite pastes. In Proc. of the $7^{\text {th }}$ Nat. Conf. on Clays and Clay Minerals, pp. 343-349. Pergamon Press, Inc. London.

Yan, L., P. F. Low, and C. B. Roth (1996). Swelling pressure of montmorillonite layers versus H-O-H bending frequence of the interlayer water. Clays and Clay Minerals 44 (6), $749-756$.

Yang, D. Q., E. E. Alonso, and H. Rahardjo (1998). Modelling the volumetric behaviour of an unsaturated expansive soil. In $2^{\text {nd }}$ Int. Conference on Unsaturated Soils, Beijing, China, Volume 2, pp. 249-254.

Yevnin, A. and D. Zaslavsky (1970). Some factors affecting compacted clay swelling. Canadian Geotechnical Journal 7, 79-91. 
Yong, R., L. O. Taylor, and B. P. Warkentin (1963). Swelling pressures of sodium montmorillonite at depressed temperature. In Proc. of the $11^{\text {th }}$ Nat. Conf. on Clays and Clay Minerals, pp. 268-281.

Yong, R. N. (1999a). Overview of modeling of clay microstructure and interactions for prediction of waste isolation barrier performance. Engineering Geology 54, 83-91.

Yong, R. N. (1999b). Soil suction and soil-water potentials in swellig clays in engineered clay barriers. Engineering Geology 54, 3-13.

Yong, R. N. and A. M. O. Mohamed (1992). A study of particle interaction energies in wetting of unsaturated expansive clays. Canadian Geotechnical Journal 29, 1060-1070.

Zhang, F., Z. Z. Zhang, P. F. Low, and C. B. Roth (1993). The effect of temperature on the swelling of montmorillonite. Clay Minerals 28, 25-31.

Zheng, Y., A. Zaoui, and I. Shahrour (2010). Evolution of the interlayer space of hydrated montmorillonite as a function of temperature. American Mineralogist 95, 1493-1499. 